\title{
Larval ecology of Anopheles coluzzii in Cape Coast, Ghana: water quality, nature of habitat and implication for larval control
}

\author{
Andreas A. Kudom*
}

\begin{abstract}
Background: There is a growing interest in larval control intervention to supplement existing malaria control strategies, particularly in urban areas. However, effective implementation requires a good understanding of habitat ecology of Anopheles mosquitoes. Clean water bodies have long been reported by several studies as a preferred breeding habitat for Anopheles gambiae. Other studies have also reported the breeding of An. gambiae in polluted water bodies. However, the term clean or polluted is mostly based on visual examination and is not well defined. This study was conducted with the aim of assessing water quality in Anopheles breeding habitats and the practicability of larval control in Cape Coast, Ghana.

Methods: A larval survey was conducted for 15 months in Cape Coast. In individual breeding habitats, habitat characteristics, physicochemical parameters and bacterial fauna were measured in both Anopheles positive breeding (APL) habitats and habitats colonized by only Culex species. The sibling species of An. gambiae were identified using PCR assay.

Results: Anopheles coluzzii dominated in almost all the APL habitats found in this study. The habitats had high levels of salinity and ammonium ions. However, ammonium ions were significantly higher $(p=0.001)$ in habitats colonized by only Culex larvae compared to APL habitats. About $47 \%$ of the habitats that were colonized by only Culex larvae had no measurable dissolved oxygen while An. coluzzii was absent in such habitats. High concentration of faecal bacteria confirmed faecal contamination in both groups of breeding habitats.

Conclusions: From the results, it was evident that larval stages of An. coluzzii have tolerance to high levels of salinity and organic pollution in breeding habitats. However, its level of tolerance to organic pollution is probably lower than Culex larvae. The nature of breeding habitats found in the city demonstrates the opportunistic behaviour of An. coluzzii and how its breeding requirements are so intimately intertwined with the haphazard and uncontrolled human activities in the urban area. Considering the nature of APL habitats, larval control intervention could greatly reduce Anopheles population. However, improving basic hygiene and sanitation in the city could even make larval control intervention more practical and cost effective.
\end{abstract}

Keywords: Anopheles, Habitat ecology, Culex, Larval control, Pollution, Urbanization

\section{Background}

Most African cities are undergoing rapid urbanization. Presently, about $53 \%$ of Ghana's entire population live in urban areas and this is projected to increase up to $70 \%$

*Correspondence: akudom@ucc.edu.gh

Department of Entomology and Wildlife, School of Biological Sciences, University of Cape Coast, Cape Coast, Ghana by 2050 [1]. This has rejuvenated interest in the challenges of urban malaria control in the country. Current malaria vector control measures include use of long lasting insecticidal nets and indoor residual spraying. However, these measures alone may be insufficient to achieve malaria elimination in Ghana and in many other endemic countries. A major limitation of the current control measures is the inability to cover the full spectrum of 
locations where mosquito exposure occurs. The existence of outdoor biting mosquitoes could prevent attainment of malaria elimination, even if it involves a small percentage of malaria vectors [2]. Additional malaria control measures are clearly required. Over the past decade there has been growing interest in larval control intervention to supplement existing malaria control strategies [3-5]. However, effective implementation requires a good understanding of habitat ecology of Anopheles mosquitoes, which is limited, especially in many urban areas in Ghana.

Comprehensive data on habitat ecology of Anopheles gambiae in urban areas in Ghana dates back more than a century [6]. Since then, there have been few studies on habitat ecology of Anopheles species, which in most cases targets specific ecological or land use settings, such as urban agricultural areas $[7,8]$. Indeed, urban agriculture is currently cited as a major breeding site for An. gambiae in many urban areas. In Kumasi (Ghana's second largest city), for example, urban agriculture is reported to be responsible for the production of over $80 \%$ of malaria mosquitoes in the city [7]. Breeding does take place in some urban areas without any important urban agriculture; however, information on Anopheles larval habitats is woefully inadequate in such urban areas. Clear ecological characteristics of Anopheles larval breeding requirements have not been identified for urban settings. Small, temporary sunny water bodies, relatively clean and mostly without overhanging vegetation have been recognized by several studies as preferred breeding habitats for $A n$. gambiae [9]. Other studies have also reported the breeding of $A n$. gambiae in large permanent and polluted water bodies $[10,11]$. However, the term clean or polluted habitat is mostly based on visual examination and is not well defined. Quantifying water quality or pollution in Anopheles breeding habitats may give more insight into Anopheles breeding requirements, particularly in urban settings.

The present study was conducted in Cape Coast to gain more insight into Anopheles larval ecology in urban settings and assess the practicability of larval control intervention in the city. Cape Coast is an urban area in the coastal savannah region of Ghana with a rich mosaic of wetland habitats but without any major commercial vegetable farming. Human activities (partly due to rapid urbanization) and/or climatic change has created or modified various larval habitats in the metropolis. Similar to the rest of the country, malaria transmission occurs throughout the year. However, Cape Coast is one of the two metropolises with high percentage malaria parasitaemia in children and the lowest percentage of households that own insecticide-treated nets among the large urban areas in Ghana (Multiple Indicator Cluster Survey 2011,
Ghana Statistical Service). There is limited information on malaria vector composition and their habitat ecology in the city.

The main objective of the study was to determine Anopheles species composition in the city and characterize their breeding habitats, with particular emphasis on water quality in the breeding habitats. Since Culex larvae are known to colonize polluted habitats, water quality of the Anopheles breeding habitats was compared to that of habitats that were colonized by Culex larvae only. A larval survey was conducted for 15 months in different landscape and land use settings in Cape Coast. Anopheles coluzzii was found to be the dominant Anopheles species, breeding in organic polluted habitats. However, the level of organic pollution appears to be lower in An. coluzzii breeding habitats compared to habitats that were colonized by only Culex larvae. Almost all the habitats were anthropogenic in nature and it seems an improvement of basic hygiene and sanitation with regards to waste management in the city could prevent the formation of many of the Anopheles breeding habitats in Cape Coast.

\section{Methods \\ Study sites}

Cape Coast is about $165 \mathrm{~km}$ west of Accra (capital of Ghana) on the Gulf of Guinea $\left(5^{\circ} 06^{\prime} \mathrm{N} 1^{\circ} 15^{\prime} \mathrm{W} ; 5.1^{\circ} \mathrm{N}\right.$ $\left.1.25^{\circ} \mathrm{W}\right)$. The city has a population of 169,894 from 2010 Census (Ghana Statistical Service) and occupies approximately $122 \mathrm{sq} \mathrm{km}$ of land. The major rainy season is between May and July with mean monthly relative humidity varying between 85 and $99 \%$. In 2014, the city recorded about 74 days with rain, totalling about $963.8 \mathrm{~mm}$ (Regional Meteorological Office, Cape Coast, Ghana). Mean monthly temperature, relative humidity and total monthly rainfall during the study period is presented in Fig. 1.

\section{Larval survey and water quality assessment}

A larval survey was conducted from January 2014 to March 2015. In the city, study sites were selected according to landscape (high/low altitude areas), land cover (swampy/non swampy areas) and land use settings (plan/ unplanned residential areas and commercial areas) (Fig. 2). The larval survey was conducted to determine temporal and spatial distribution of Anopheles species in the study sites. There are two seasons in Ghana: dry and rainy, and a larval survey was conducted during the peak of each of the season. Dry season was a season of interest due to limited traditional habitats (water pools) for Anopheles species; the survey was conducted in two dry seasons: January-March 2014 and January-March 2015, and data for the rainy season were collected during MayJuly 2014. 


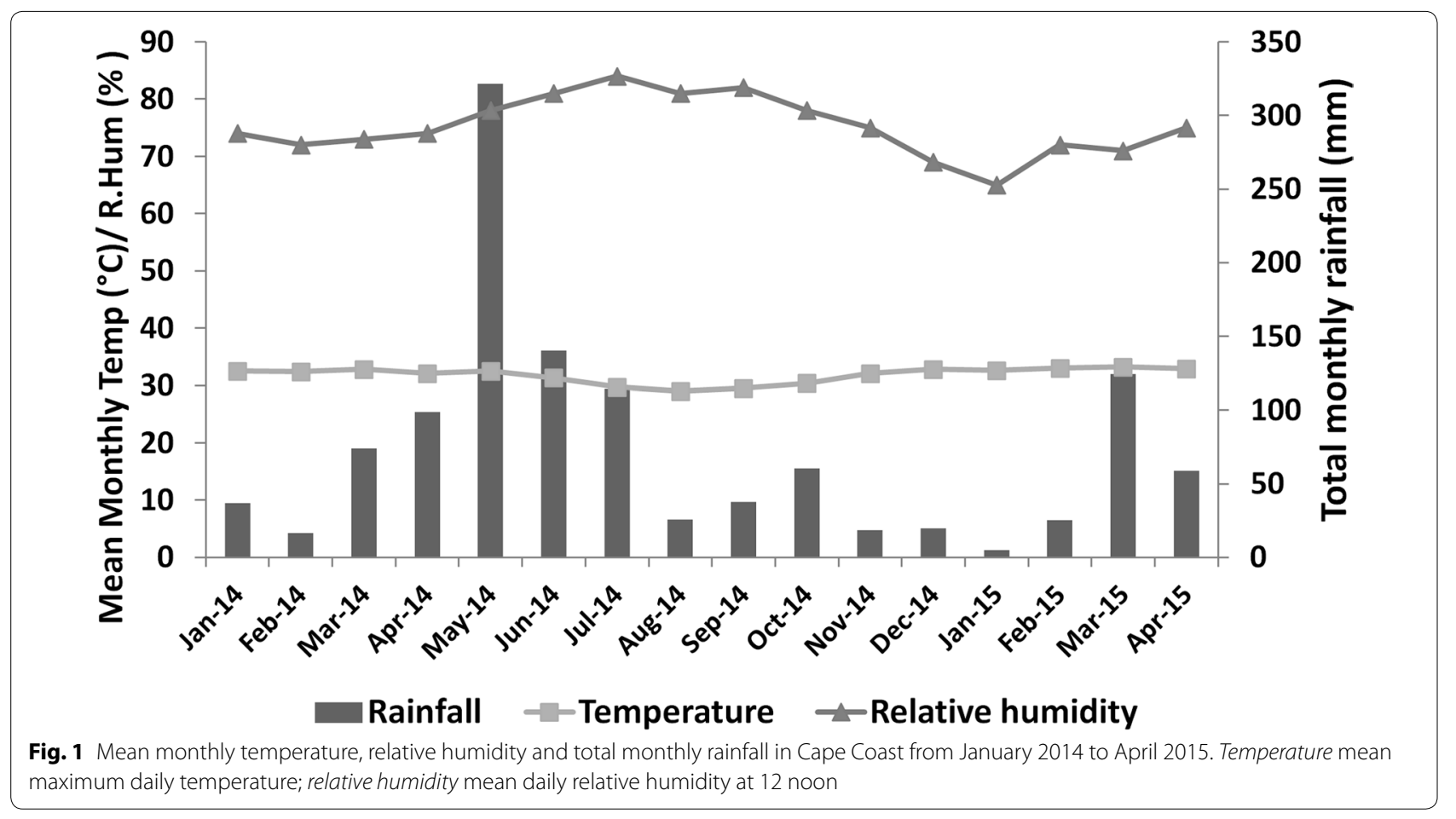

Each study site was monitored once every fortnight for the three-month period for each of the three seasons (2014 dry season, rainy season and 2015 dry season). All open water bodies in the study sites were explored on both public and private properties. When a larval positive breeding habitat was found, the habitat was monitored once every fortnight for 2 months (if a larval positive habitat was found close to the end of a season, the two-month monitoring continued after the end of that season). For every visit, mosquito larvae were sampled and water quality characterized according to some selected water quality parameters. This monitoring protocol was done to gain insight into temporal dynamics of breeding habitats and the impact on species composition and spatial distribution of Anopheles, as well as to determine longevity of the breeding habitats.

Habitats were characterized using a standard format for each site, including water quality, nature and features of habitats, and presence or absence of vegetation in the breeding sites. Water quality was characterized by temperature, $\mathrm{pH}$, dissolved oxygen, salinity, conductivity, and ammonia (non-ionized (NH3) and ionized $\left(\mathrm{NH} 4^{+}\right)$) and bacteria fauna. These water quality parameters were selected to give basic physical characteristics of the breeding habitats as well as the level of organic pollution in the habitats. With the exception of total coliform, water quality parameters measured were performed in the field using a portable meter (YSI Professional Plus,
YSI Inc, Yellow Springs, OH, USA and Oakton PCD650, Oakton Instruments, IL, USA). Using pour plate method, the concentration of bacterial population was determined in individual breeding habitats. Organisms showing similar morphological characteristics were sub-cultured. The Gram staining procedure was performed on all the individual and different (morphologically) colonies on Petri dishes to ascertain the cellular shape and arrangement. Individual colonies were identified according to the procedure described by Leboffe and Pierce [12].

Mosquito larvae collected from each breeding habitat were reared to adult in a separate and labelled rearing tray covered with netting and placed in an emergence chamber. The emergence chamber was made up of a wooden box covered with a 1-sq mm nylon mesh and a transparent roof. Light intensity, temperature and relative humidity in the chamber were similar to that of the outside environment. The larvae were reared in water taken from the habitat from which the mosquito was collected. GPS location were recorded with Garmin (eTrex $\left.{ }^{\circledR} 10\right)$ and $\mathrm{iPad}^{\circledR}$ (Apple Inc.) using an application by Petosoft ${ }^{\circledR}$.

\section{Assessing basic knowledge on the aquatic stages of mosquitoes and their breeding habitats}

A qualitative study in the form of a short interview with property owners, where the larval survey was conducted on their properties, was conducted to assess their basic knowledge of the aquatic stages of mosquitoes and their 


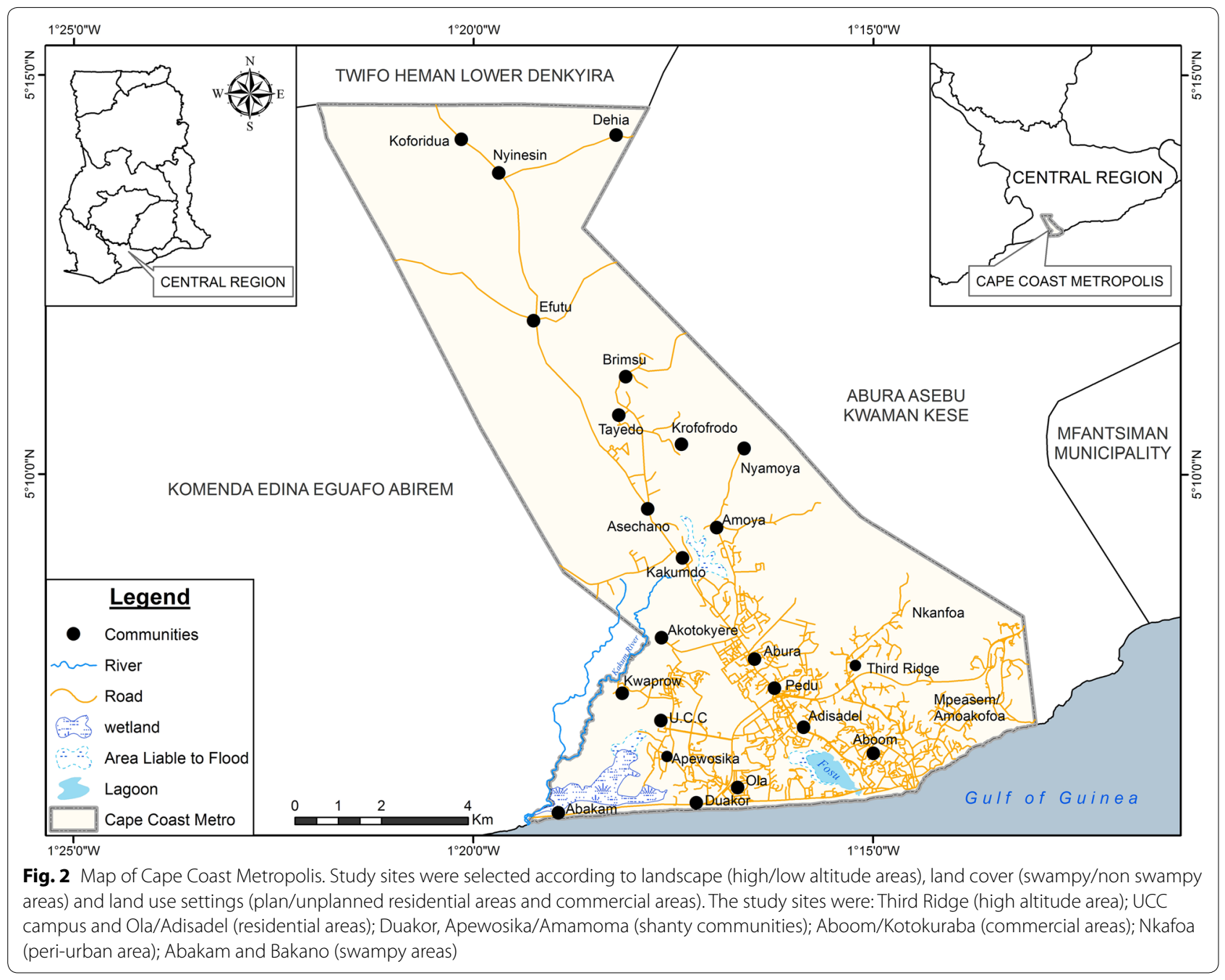

breeding habitats. Most of the private properties comprised construction sites, uncompleted buildings and residential buildings without fencing. Facilities such as gutters, cesspits, open water-tanks/reservoirs, open wells, and newly constructed septic tanks which were yet to be covered, were explored for larvae. An interview lasting between 10 and 15 min was conducted for each of the participants. Ten participants were selected based on following criteria: (1) being present on their property during the larval survey; (2) accepted to be interviewed; and, (3) presence of mosquito larval habitat on their property. As part of the interview, the participants were: (1) shown mosquito larvae to identify; (2) asked to mention mosquito breeding places they knew of; and, (3) to describe the stages of mosquito development. Permits and approvals were not required for this study. However, permission was sought from private property owners or caretakers to conduct the larval survey on their properties.

\section{Molecular species identification}

Adult mosquitoes that emerged from the larvae collected from breeding habitats were morphologically identified according to Gillies and Coetzee [13]. Further molecular identification was conducted on about 20 individuals from randomly selected habitats from each of the study sites. The PCR assay was conducted according to the procedure described by Scott et al. [14]. The two species, An. coluzzii (formerly An. gambiae M molecular form and hereafter An. coluzzii) and An. gambiae (formerly An. gambiae S molecular form and hereafter An. gambiae) were further identified using the SINE PCR method described by Santolamazza et al. [15]. Culex species were also morphologically identified and followed by PCR to confirm Culex quinquefasciatus using the method described by Smith and Fonseca [16]. Genomic DNA was extracted using QIAGEN DNeasy kit according to the manufacturer's instructions. 


\section{Data analysis}

Physicochemical parameters and concentration of bacterial population were compared between Anopheles-positive breeding sites and habitats colonized by only Culex species using Mann-Whitney $U$ test. The habitats were map using ESRI's ArcMap software.

\section{Results}

\section{Distribution of Anopheles species in Cape Coast}

All the Anopheles larvae that were collected and reared to adult were morphologically identified as An. gambiae s.l. Out of 262 individuals that were identified by PCR assay, $91 \%$ were $A n$. coluzzii whereas $8.7 \%$ were An. gambiae. Anopheles melas was about $0.3 \%$ and was only found during the dry season (Table 1). Surprisingly, none of the 150 individual Culex species was positive for C. quinquefasciatus from the PCR diagnostic assay.

\section{Water quality parameters in Anopheles breeding habitats}

The median and interquartile range (IQR) of different water quality parameters measured in Anophelespositive habitat (APL habitat) and habitats colonized by only Culex larvae are presented in Table 2. A two-tailed Mann-Whitney $U$ test showed that APL habitats had higher temperature, $\mathrm{pH}$, dissolved oxygen and lower ionized ammonia $\left(\mathrm{NH}_{4}^{+}\right)$compared to breeding habitats with only Culex larvae. Furthermore, APL breeding habitats were slightly high in salinity with a median (IQR) of $0.8 \mathrm{ppt}(0.4-2.3)(\mathrm{N}=72)$. Interestingly, about $48 \%$ (22/46) Culex only habitats had no measurable dissolved oxygen (anoxic habitats) whereas APL breeding sites had a median (IQR) of $7.6 \mathrm{mg} / \mathrm{l}(4.6-8.8)$ of dissolved oxygen. Non-ionized ammonia (NH3) level was similar in the two habitats but ionized ammonia $\left(\mathrm{NH}_{4}^{+}\right)$ was significantly higher $(\mathrm{p}=0.001)$ in habitats colonized by only Culex larvae compared to APL habitats (Table 2). The median (IQR) of bacterial concentration in APL habitats was $49(36.5-59) \times 10^{3} \mathrm{cfu} / \mathrm{ml}(\mathrm{N}=21)$, which was similar in habitats colonized by only Culex larvae, 42 $(22-78) \times 103 \mathrm{cfu} / \mathrm{ml}(\mathrm{N}=27)(\mathrm{p}=0.908)$. Most of the bacterial fauna that were identified belong to the thermotolerant (faecal) coliforms. Five species: Escherichia coli, Clostridium species, Klebsiella pneumoniae, Enterobacter aerogenes, and Salmonella species were present in all the individual habitats (Table 3).

Within large APL breeding habitats, it was observed that Anopheles larvae were mostly confined to specific areas or spots whereas Culex larvae were relatively evenly distributed. Physicochemical measurements in the Anopheles-confined areas and other areas with only Culex larvae revealed variations in water quality (Figs. 3, 4). This was more evident in the level of dissolved oxygen and temperature. Dissolved oxygen and temperature
Table 1 Anopheles species composition over space and time in Cape Coast, Ghana

\begin{tabular}{|c|c|c|c|c|}
\hline Habitat & Community & Date & Season & $\begin{array}{l}\text { Anopheles } \\
\text { species (N) }\end{array}$ \\
\hline Pool of water & Bakano & January 2014 & & An. coluzzii (5) \\
\hline Pond & Abakam & $\begin{array}{l}\text { February } \\
2014\end{array}$ & & An. melas (1) \\
\hline Pool of water & Duakro & $\begin{array}{c}\text { February } \\
2014\end{array}$ & & An. coluzzii (20) \\
\hline Stream & UCC campus & $\begin{array}{l}\text { February } \\
2014\end{array}$ & & An. coluzzii (20) \\
\hline Pool of water & Apewosika & March 2014 & Dry & $\begin{array}{r}\text { An. coluzzii (4); } \\
\text { An. melas (1) }\end{array}$ \\
\hline Pool of water & Amamoma & March 2014 & & An. coluzzii (16) \\
\hline Pond & Amamoma & March 2014 & & An. coluzzii (20) \\
\hline Pool of water & Apewosika & March 2014 & & An. coluzzii (1) \\
\hline Pool of water & Apewosika & May 2014 & & An. coluzzii (20) \\
\hline Tyre track & Amamoma & May 2014 & & $\begin{array}{l}\text { An. coluzzii (2); } \\
\text { An. gambiae } \\
\text { (3) }\end{array}$ \\
\hline Rain pool & Adisadel & June 2014 & Rainy & An. coluzzii (20) \\
\hline Pothole & North Ola & June 2014 & & An. coluzzii (20) \\
\hline Tyre track & North Ola & June 2014 & & An. coluzzii (20) \\
\hline Pool of water & Abura & July 2014 & & An. coluzzii (20) \\
\hline $\begin{array}{l}\text { Choked gut- } \\
\text { ter }\end{array}$ & North Ola & January 2015 & & An. coluzzii (20) \\
\hline Stream & UCC campus & January 2015 & & An. coluzzii (9) \\
\hline Concrete tank & North Ola & January 2015 & Dry & An. coluzzii (20) \\
\hline Gutter & Nkafoa & $\begin{array}{l}\text { February } \\
2015\end{array}$ & & $\begin{array}{l}\text { An. gambiae } \\
(20)\end{array}$ \\
\hline
\end{tabular}

were higher in specific areas where Anopheles larvae were mostly found compared to areas with only Culex larvae.

\section{Nature of Anopheles breeding habitats}

Several water-holding facilities in houses and at construction sites, wells, broken pipes, choked gutters, and a wide range of water pools were the major Anopheles larval habitats in the study sites (Fig. 5).

Large numbers of APL habitats in the form of puddles, tyre tracks, rain pools, and potholes were observed. It appears most depressions that can hold water during the rainy season were colonized by Anopheles. For example, within a 100-m section of a road (Fig. 5a), about 50 individual APL habitats were counted and several of such roads were observed in the study sites. Interestingly, most of these habitats were on public properties, such as public roads and constructed waterways (Fig. 5b).

During the dry season, APL habitats were mostly choked gutters and different types of water receptacles, including concrete and plastics containers. Some transitory habitats were also found after a few rainfalls recorded in the two dry seasons. The first dry season 
Table 2 The median (IQR) of physicochemical parameters in mosquito breeding habitats in Cape Coast

\begin{tabular}{|c|c|c|c|c|}
\hline \multirow[t]{2}{*}{ Water quality parameter } & \multicolumn{4}{|c|}{ Type of breeding habitats* } \\
\hline & $\begin{array}{l}\text { Pool of water } \\
\text { (APL habitat) }(N=20)\end{array}$ & $\begin{array}{l}\text { Choked gutters } \\
\text { (APL habitat) }(\mathrm{N}=5)\end{array}$ & $\begin{array}{l}\text { All APL habitats }{ }^{\#} \\
(N=72)\end{array}$ & $\begin{array}{l}\text { Culex only habitats }{ }^{\#} \\
(\mathrm{~N}=46)\end{array}$ \\
\hline Temp ${ }^{\circ} \mathrm{C}$ & $36.7(35.6-37.9)$ & $33.9(33.3-34.4)$ & $34.9^{\mathrm{a}}(33.4-37.1)$ & $31^{b}(29.5-32.4)$ \\
\hline $\mathrm{pH}$ & $7.6(7.1-8.0)$ & $8.8(8.2-8.9)$ & $8.1^{\mathrm{a}}(7.3-8.6)$ & $7.3^{b}(6.9-7.7)$ \\
\hline $\mathrm{DO} \mathrm{mg} / \mathrm{l}$ & $5.2(3.1-6.8)$ & $8.8(8.5-11.5)$ & $7.6^{\mathrm{a}}(4.6-8.8)$ & $0.2^{\mathrm{a}}(0-0.8)$ \\
\hline Sal ppt & $0.87(0.5-1.4)$ & $0.94(0.9-1.5)$ & $0.8^{\mathrm{a}}(0.4-2.3)$ & $0.6^{\mathrm{a}}(0.5-0.7)$ \\
\hline $\mathrm{SC} \mu \mathrm{s} / \mathrm{cm}$ & $1743(977-2680)$ & $1518(1210-2668)$ & $1452.5^{\mathrm{a}}(793-4209)$ & $1052^{\mathrm{a}}(667-1439)$ \\
\hline TDS mg/l & $1134(511-1742)$ & $988(953-1492)$ & $952.9^{\mathrm{a}}(435-2371)$ & $600^{\mathrm{a}}(521-979)$ \\
\hline Res ohm-cm & $466(375-1055)$ & $537(394-546)$ & $545.8^{\mathrm{a}}(226-1169)$ & $729.2^{\mathrm{a}}(537-1010)$ \\
\hline $\mathrm{NH} 4^{+} \mathrm{mg} / /^{\S}$ & $3.4(3-3.7)$ & $16.5(9.7-23.2)$ & $3.3^{\mathrm{a}}(2.4-4.2)$ & $35.7^{b}(29.9-68.1)$ \\
\hline $\mathrm{NH} 3 \mathrm{mg} / \mathrm{l}^{\S}$ & $0.5(0.4-1.2)$ & $3.2(2.6-3.8)$ & $0.6^{\mathrm{a}}(0.2-1.8)$ & $0.9^{\mathrm{a}}(0.7-1.8)$ \\
\hline
\end{tabular}

* APL habitats (Anopheles positive habitats) comprises habitats that were either being colonized by only Anopheles or both Anopheles and Culex species, whereas Culex only habitats were habitats that were colonized by only Culex species

\# Values in 'All APL habitats' and Culex only habitats for each water quality parameter sharing same letter are not significantly different; (IQR inter-quartile range, Temp temperature, DO dissolved oxygen, Sal salinity, SC specific conductivity, TDS total dissolved solids, Res resistivity, $\mathrm{NH}^{+}{ }^{+}$ionized ammonia, $\mathrm{NH} 3$ non-ionized ammonia)

$\S$ Ammonia ions were not measured in habitats that had salinity of 1 ppt or more

Table 3 The median (IQR) of concentration of bacterial fauna in mosquito breeding habitats in Cape Coast

\begin{tabular}{|c|c|c|}
\hline Type of breeding habitat ${ }^{a}$ & $\begin{array}{l}\text { Median (IQR) of total } \\
\text { viable count }\left(\times 10^{3} \mathrm{cfu} / \mathrm{ml}\right)\end{array}$ & Bacterial species $^{\mathbf{b}}$ \\
\hline $\begin{array}{l}\text { Anopheles-positive breeding } \\
\text { habitats }(\mathrm{N}=21)\end{array}$ & $49(36.5-59)$ & $\begin{array}{l}\text { Enterobacter cloacae, Proteus mirabilis, Streptococcus } \\
\text { faecalis, Shigella sp., Klebsiella oxytoca, Staphy- } \\
\text { lococcus aureus, Escherichia coli, Clostridium sp., } \\
\text { Klebsiella pneumoniae, Enterobacter aerogenes, } \\
\text { Salmonella sp. }\end{array}$ \\
\hline Culex only habitats $(\mathrm{N}=27$ ) & $42(22-8)$ & $\begin{array}{l}\text { Citrobacter spp., Shigella spp, Streptococcus faecalis, } \\
\text { Proteus mirabilis, Klebsiella oxytoca, Staphylo- } \\
\text { coccus aureus, Escherichia coli, Clostridium sp., } \\
\text { Klebsiella pneumoniae, Enterobacter aerogenes, } \\
\text { Salmonella sp. }\end{array}$ \\
\hline
\end{tabular}

a Bacteria fauna was assessed in these breeding habitats during the dry season (January-March 2014)

b Five species: Escherichia coli, Clostridium species, Klebsiella pneumoniae, Enterobacter aerogenes, Salmonella species were present in all individual habitats

(January-March 2014) recorded about 13 days of rainfall totalling $127.2 \mathrm{~mm}$, whereas the second dry season (January-March 2015) recorded about 11 days of rainfall totalling $154.5 \mathrm{~mm}$. The rainfall pattern differs slightly between the two dry seasons, which consequently affected the distribution of APL habitats in the two seasons. For example, only a single rainfall of $5 \mathrm{~mm}$ was recorded for January 2015 whereas 3 days of rainfall of $36.8 \mathrm{~mm}$ was recorded in January 2014. Hence, it was not surprising that transitory habitats such as water puddles and water pools were recorded in January 2014 but only gutters and water reservoirs (Fig. 5g) were recorded in January 2015.

The spatial distribution of mosquito breeding habitats during the dry season is presented in Fig. 6. The mean \pm SD elevation where APL habitats were found was $11.5 \pm 2.3 \mathrm{~m}$ (Fig. 7). Most APL habitats were found around lowland areas or areas close to wetlands.

The longevity of habitats varied greatly. Some breeding habitats existed for a few days, some weeks and others throughout the year. While some habitats were colonized by Culex larvae throughout the study period, none of the breeding habitats was found harbouring Anopheles larvae for an entire season. Besides habitats drying up, the conditions of some of the habitats changed and this in turn affects the colonization of Anopheles larvae in time. The two main factors that were observed to cause changes in habitat conditions were changes in water quality (Fig. 4) and vegetation cover (weeds covering the habitat). Also, heavy downpour was a major factor during the rainy season. 


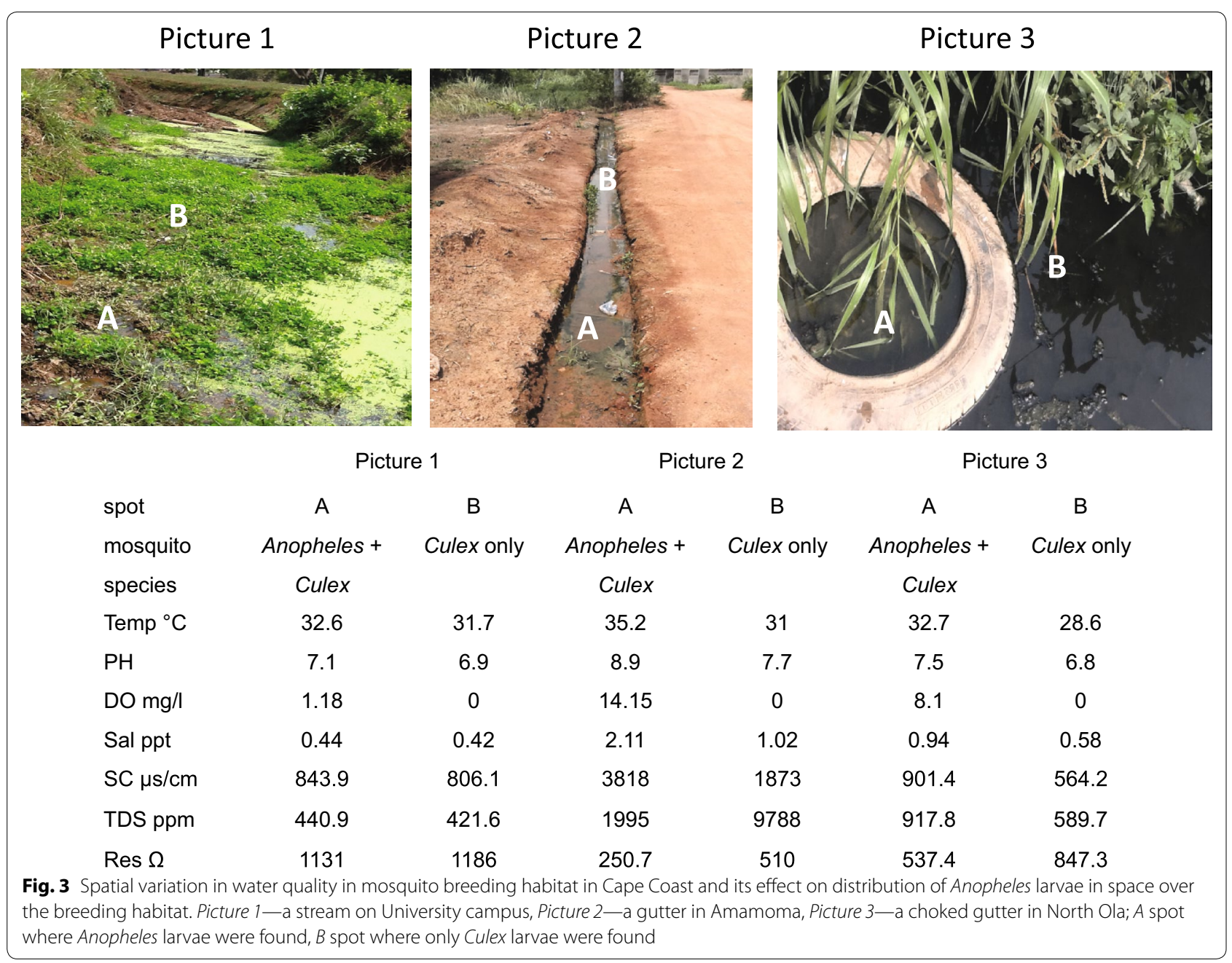

\section{Basic knowledge on the aquatic stages of mosquitoes and their breeding habitats}

None of the ten private property owners/caretakers was able to correctly identify the mosquito larvae shown to them nor able to describe the developmental stages of a mosquito. Most of them have seen mosquito larvae before but wrongly thought they were tadpoles (immature stage of a frog), worms or something other than a mosquito. However, they all know that mosquitoes breed in stagnant water bodies but were not aware that concrete tanks and other water-holding receptacles on their properties were breeding mosquitoes. For instance, when asked to describe the developmental stages of a mosquito, one participant who was a nurse by profession said

"I know they lay eggs in stagnant waters. I am not sure what happens after that, but, I think immediately after the eggs hatches they fly away". Like others, she only knew the adult stage of a mosquito.

\section{Discussion}

Understanding the ecological drivers that are responsible for modulating the distribution and habitat segregation of Anopheles species is of paramount importance in malaria control. In the present study, An. coluzzii, An. gambiae and $A n$. melas belonging to An. gambiae complex were found in Cape Coast but their abundance and distribution varied. Anopheles coluzzii dominated in almost all the breeding habitats and was found actively breeding in both rainy and dry seasons in diverse habitats. Habitats that were colonized by $A n$. coluzzii during the rainy season (footprints, tyre tracks, rain pools) are consistent with the known preference of An. gambiae, particularly in rural areas [17]. However, salinity was relatively high in breeding habitats found in this study. In the dry season, An. coluzzii was mostly found cohabiting with Culex species in choke gutters and other organic polluted 


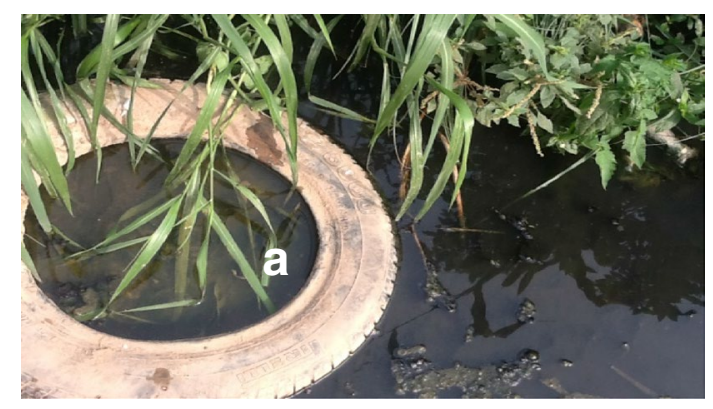

A

Date of larval survey

Breeding status of Anopheles species

Temp ${ }^{\circ} \mathrm{C}$

$\mathrm{PH}$

DO mg/l

Sal ppt

$\mathrm{SC} \mu \mathrm{s} / \mathrm{cm}$

TDS mg/l

$\operatorname{Res} \Omega$

$\mathrm{NH}^{+} \mathrm{mg} / \mathrm{l}^{\S}$

$\mathrm{NH} 3 \mathrm{mg} / \mathrm{l}$
5 January, 2015

Presence of Anopheles coluzzii Absence of Anopheles species

32.7

35.5

7.5

6.5

8.1

0

0.94

1.25

901.4

1185.0

917.8

1246.0

537.4

410.4

26.25

31.95

0.86

0.08

Fig. 4 Temporal changes in water quality in a mosquito breeding habitat in Cape Coast and its effect on the distribution of Anopheles larvae in time in the breeding habitat. a water quality measured in 5 January, 2015; b water quality measure in 19 January, 2015

habitats, which was indicated by high levels of ammonia ions. This is not surprising because from both laboratory experiments [18] and field observations $[6,10,11,19]$, it is becoming clearer that $A n$. coluzzii exhibit some degree of tolerance to high salinity and ammonia ions.

The high prevalence of $A n$. coluzzii in this study is consistent with previous studies in the country. Previous studies in Ghana have shown An. gambiae and $A n$. coluzzii sympatrically co-existing in most locations. However, $A n$. gambiae predominate in the central part of the country whereas An. coluzzii and Anopheles arabiensis predominate in the northern and coastal savannah regions, with $A n$. melas occurring mainly at the coastal areas $[20,21]$. The result also conforms to the continental species distribution model that has been described by Tene-Fossog and colleagues [22], which predicted predominance of $A n$. coluzzii along the coastline of west and central Africa. High level of salinity observed in the breeding habitats colonized by $A n$. coluzzii may have contributed to its high prevalence in Cape Coast [22]. The only habitat that An. gambiae dominated was found at the peripheral part of the city, away from the core of the densely urbanized area and away from the coast.

The dominance of $A n$. coluzzii in coastal areas of Ghana has been explained by the wide presence of permanent breeding conditions from irrigation facilities and ponds, resulting from river run-off [20, 21]. Similarly, along its geographical distribution, An. coluzzii is seen to predominate in areas characterized by larger, more temporally stable breeding sites, such as rice paddies and 

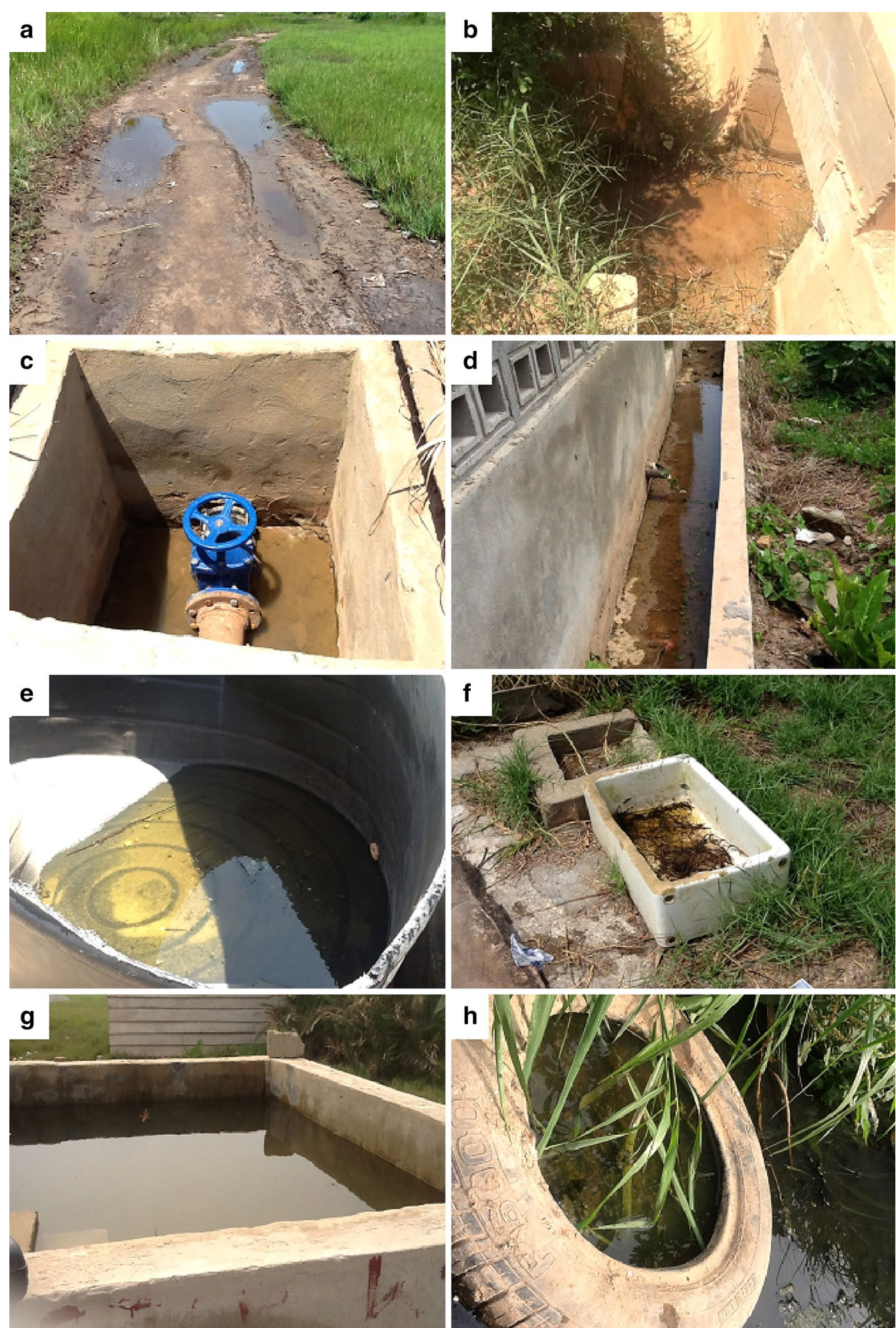

Fig. 5 Some major Anopheles positive breeding habitats in Cape Coast. During the rainy (a-d) and dry (e-h) seasons; $\mathbf{a}$, b water puddles on a public road and waterway; c water pool in a concrete receptacle holding a stopcock of a public water pipeline; $\mathbf{d}$ : poorly drained gutter in a private residential property; $\mathbf{e}, \mathbf{f}$ abandoned water-holding containers on private properties; $\mathbf{g}$ concrete water tank at a private construction site; $\mathbf{h}$ choked gutter with high input of solid and liquid waste from households 


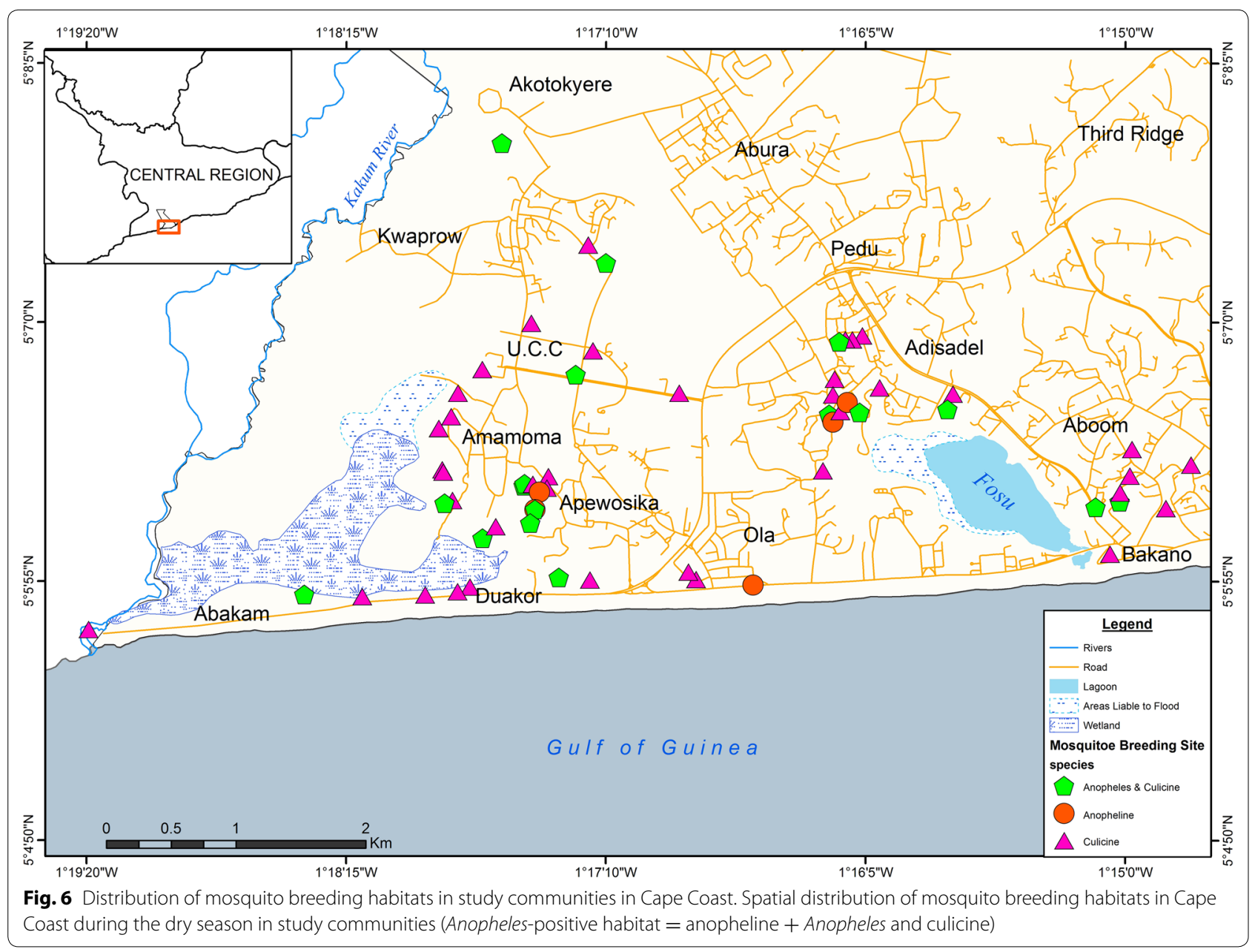

irrigation facilities [23-25]. On the contrary, this study found An. coluzzii breeding in small ephemeral habitats similar to that described for An. gambiae. Additionally, An. coluzzii and Culex larvae co-existed in marginal habitats such as organic polluted habitats, particularly during the dry season. The absence of An. coluzzii in marginal habitats during the rainy season may suggest that it also has preference for temporary aquatic habitats. However, in the absence of preferred habitat, its ability to tolerate high ions such as ammonia and salinity, perhaps, makes it possible to breed in marginal habitats to maintain its population during unfavourable season.

Considering the diverse nature of APL habitats and different levels of water quality in breeding habitats, further insight could be gained from investigations of chronic exposure of An. coluzzii to organic pollution and its impact on life-history traits. Mireji and colleagues [26] showed that An. gambiae that developed tolerance to some heavy metals occurred at a significant biological cost to the mosquito, adversely affecting its ecological fitness. Similarly, intensive mortality was observed in the early instars of Culex tarsalis that bred in poor water quality habitats [27]. Surprisingly, C. quinquefasciatus, a common mosquito species in organic polluted waters, was absent in this study and it is consistent with a previous study in Cape Coast [28]. The reason for the absence of this cosmopolitan and widely distributed species is not presently clear.

Water quality in the breeding habitats seems to be affected by natural and human influences. On the one hand, the habitats were high in salinity, electrical conductivity and total dissolved solids, which may have been as a result of proximity to the sea, although anthropogenic factors cannot be ruled out. On the another hand, low dissolved oxygen, high ammonia ions and high concentration of thermotolerant bacterial coliforms in some APL habitats may have been caused by organic pollution resulting from high input of solid and liquid waste from households. Presence of faecal bacteria such as Escherichia coli, faecal streptococci and other coliforms also confirmed faecal contamination in the breeding habitats. Nevertheless, a lower level of total ammonia in APL 


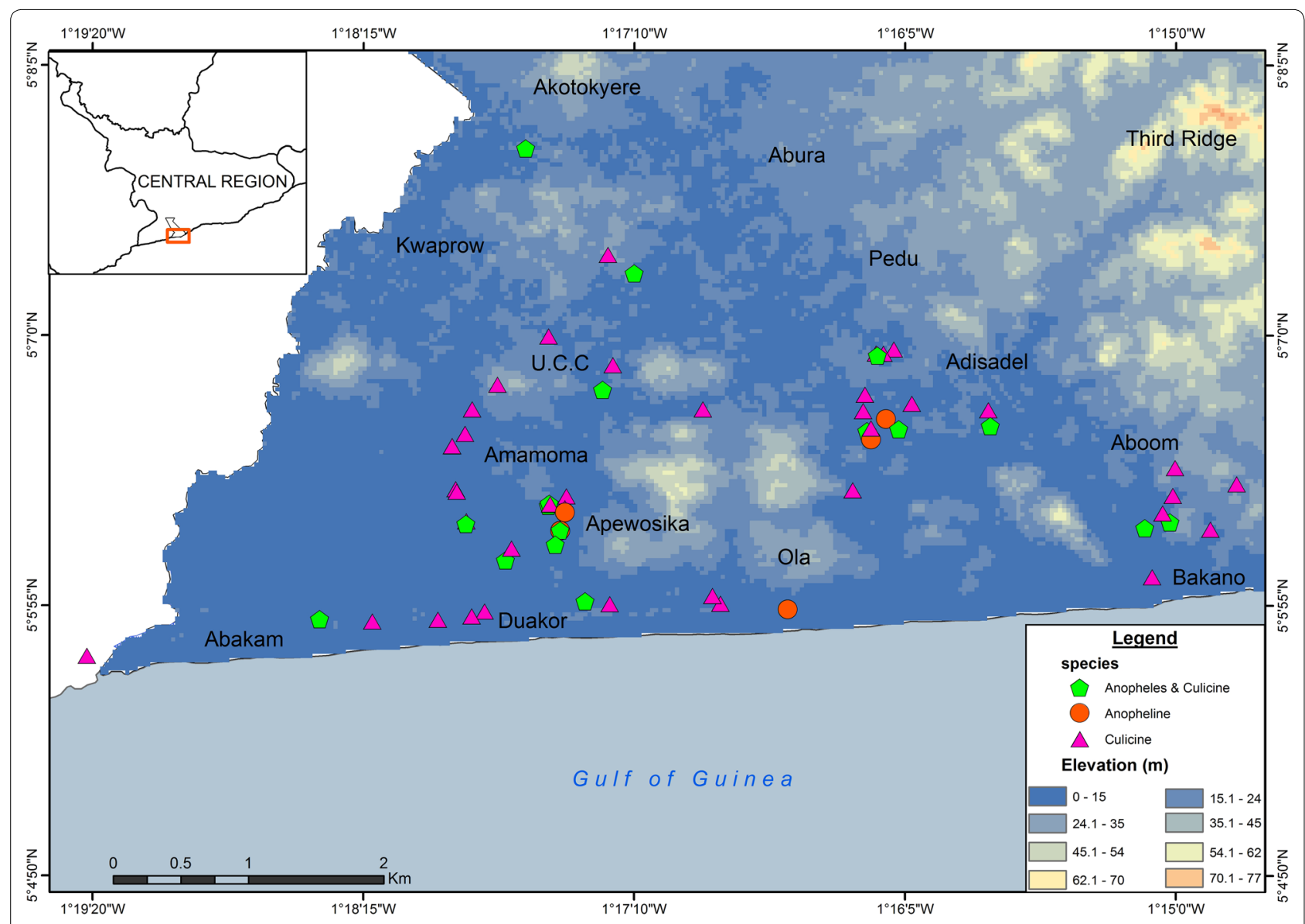

Fig. 7 Distribution of mosquito breeding habitats according to elevation in Cape Coast. Spatial distribution of mosquito breeding habitats in Cape Coast during the dry season according to elevation (Anopheles-positive habitat $=$ anopheline + Anopheles and culicine)

habitats compared to habitats colonized by Culex larvae only and the absence of An. coluzzii in anoxic breeding habitats suggests that its tolerance to organic pollution is probably lower than Culex larvae. This is further supported by the distribution of An. coluzzii in space and time in marginal habitats, which appears to be influenced by some level of water quality, notably temperature and dissolved oxygen (Figs. 3, 4). Interestingly, similar levels of non-ionized ammonia (NH3) were found in APL habitats and habitats colonized only by Culex larvae, which could indicate that the toxic effect of ammonia might be similar in both species since non-ionized ammonia is the principal toxic form of ammonia to organisms.

The rapid urbanization being witnessed in many cities in Africa is associated with pollution and environmental modification. This can create or modify various mosquito larval habitats, which in turn can affect vector composition or distribution. Unlike Cameroon where the impact of urbanization on the prevalence of An. coluzzii has been extensively studied [11], there is no such detailed information available in Ghana and most West African countries. The two highly urbanized areas in the country, Accra (coastal savannah zone) and Kumasi (forest zone) are dominated by An. coluzzii and An. gambiae, respectively. From previous studies, ecological influence rather than urbanization appears to be of greater importance in the distribution of An. gambiae species in Ghana [20, 21, 29]. Ecological factors such as elevation, precipitation and temperature have been shown to be important variables driving the spatial distribution of each of the An. gambiae species [22]. A country-wide assessment of water quality and species distribution may give a clearer picture of the role of urbanization in modulating the distribution of An. gambiae species in Ghana. Presently, there is limited information of water quality levels in Anopheles breeding habitats in the country. For example, data on level of salinity, ammonia ions and other water quality indicators in Anopheles breeding habitats are virtually absent for the central to northern part of Ghana. The few existing data are mostly found for the coastal areas [30-32].

Most of the APL habitats encountered in this study are consistent with reports from larval surveys conducted 
piecemeal in other urban areas in Ghana [6, 8, 30, 32] and several urban African countries [10, 11, 33]. Although habitat productivity, which was not assessed in this study, could differ from one habitat to other, it was more evident that the importance of habitats shifted from one habitat type to other with time since no habitat was continuously colonized for an entire season. It seems each type of breeding habitat, regardless of its level of productivity or importance, contributed to the production and maintenance of Anopheles species throughout the year. Most of the breeding habitats found in this study occurred as a result of haphazard and uncontrolled human activities. With the nature of breeding habitats in the study area, larval control intervention could greatly reduce Anopheles population in the city, particularly during the dry season. This may require constant monitoring of larval habitats and improvement of sanitation conditions in the city with regards to waste management. Ironically, there are in existence sanitation and by-laws in Ghana (Ghana Public health Act 851, 2012) that could prevent the formation of many of the Anopheles breeding habitats, however they are rarely enforced. Moreover, from the qualitative study with some of the private property owners, it appears they have inadequate knowledge of the immature stages of mosquitoes and their breeding habitats. Yet, community engagement is one of the most important aspects of mosquito management programmes. Therefore, the following: (1) proper waste management and maintenance of public roads; (2) strict enforcement of hygiene and sanitation bylaws; and, (3) community education on mosquito biology and their breeding places in the local environment could prevent formation of many mosquito breeding habitats, which could make larval control more feasible and cost effective in Cape Coast.

\section{Conclusions}

Anopheles coluzzii was found breeding in organic or faecal polluted habitats. Water in most of the breeding habitats either had high level of salinity or ammonia ions, which may be related to the proximity to the coast or urbanization, respectively. Furthermore, high concentration of bacterial fauna including several species of faecal coliforms confirms presence of organic pollution and faecal contamination in An. coluzzii breeding habitats. Organic pollution was lower in An. coluzzii breeding habitats than Culex only habitats. The nature of breeding habitats found in the city demonstrates the opportunistic behaviour of $A n$. coluzzii and how its breeding requirements are so intimately intertwined with the haphazard and uncontrolled human activities in the urban area. Considering the nature of APL habitats, improving basic hygiene and sanitation in the city could make larval control intervention more practical and cost effective.

\section{Acknowledgements}

This study was funded by The British Ecological Society (grant number 4767/5805). I acknowledge the support from the Department of Entomology and Wildlife, University of Cape Coast, Ghana.

\section{Competing interests}

The author declares that he has no competing interests.

Received: 4 June 2015 Accepted: 4 November 2015

Published online: 11 November 2015

\section{References}

1. World Urbanisation Prospects. The 2014 Revision. http://www.esa.un.org/ unpd/wup/Highlights/WUP2014-Highlights.pdf. Accessed May, 2014.

2. Govella NJ, Ferguson $\mathrm{H}$. Why use of interventions targeting outdoor biting mosquitoes will be necessary to achieve malaria elimination. Front Physiol. 2012;3:199.

3. Keiser J, Utzinger J, Castro MC, Smith TA, Tanner M, Singer BH. Urbanisation in sub-Saharan Africa and implication for malaria control. Am J Trop Med Hyg. 2004;71:118-27.

4. Killeen GF, Seyoum A, Knols BG. Rationalizing historical successes of malaria control in Africa in terms of mosquito resource availability management. Am J Trop Med Hyg. 2004;71:87-93.

5. Worrall E, Fillinger U. Large-scale use of mosquito larval source management for malaria control in Africa: a cost analysis. Malar J. 2011;10:338.

6. Chinery WA. Effects of ecological changes on the malaria vectors Anopheles funestus and the Anopheles gambiae complex of mosquitoes in Accra, Ghana. Trop Med Int Health. 1984;87:75-81.

7. Afrane YA, Klinkenberg E, Drechsel P, Owusu-Daaku K, Garms R, Kruppa T. Does irrigated urban agriculture influence the transmission of malaria in the city of Kumasi, Ghana? Acta Trop. 2004;89:125-34.

8. Klinkenberg E, McCall PJ, Wilson MD, Amerasinghe FP, Donnelly MJ. Impact of urban agriculture on malaria vectors in Accra, Ghana. Malar J. 2008;7:151.

9. Muirhead-Thomson RC. Mosquito behaviour in relation to malaria transmission and control in the tropics. London: Edward Arnold \& Co.; 1951.

10. Sattler MA, Mtasiwa D, Kiama M, Premji Z, Tanner M, Killeen GF, et al. Habitat characterization and spatial distribution of Anopheles sp. mosquito larvae in Dares Salaam (Tanzania) during an extended dry period. Malar J. 2005;4:4.

11. Kamdem C, TeneFossog B, Simard F, Etouna J, Ndo C, Kengne P, et al. Anthropogenic habitat disturbance and ecological divergence between incipient species of the malaria mosquito Anopheles gambiae. PLoS One. 2012;7:e39453.

12. Leboffe MJ, Burton EP. Microbiology laboratory theory and application. Englewood: Morton Publishing Company; 2010.

13. Gillies, MT, Coetzee M: A supplement to the Anophelinae of Africa south of the Sahara (Afrotropical region). Publications of the South African Institute for Medical Research, no. 55. SAIMR, Johannesburg 1987.

14. Scott JA, Brogdon WG, Collins FH. Identification of single specimens of the Anopheles gambiae complex by the polymerase chain reaction. Am J Trop Med Hyg. 1993;49:520-9.

15. Santolamazza F, Calzetta M, Etang J, Barrese E, Dia I, Caccone A, et al. Distribution of knock-down resistance mutations in Anopheles gambiae molecular forms in west and west-central Africa. Malar J. 2008;7:74.

16. Smith $J$, Fonseca DM. Rapid assays for identification of members of the Culex (Culex) pipiens complex, their hybrids, and other sibling species (Diptera: Culicidae). Am J Trop Med Hyg. 2004;70:339-45.

17. Clements AN. The biology of mosquitoes: development, nutrition and reproduction. Amsterdam: Kluwer Academic Publishers; 1992.

18. Tene Fossog B, Antonio-Nkondjio C, Kengne P, Njiokou F, Besansky NJ, Costantini C. Physiological correlates of ecological divergence along an urbanisation gradient: differential tolerance to ammonia among molecular forms of the malaria mosquito Anopheles gambiae. BMC Ecol. 2013;13:1. 
19. Fillinger U, Sonye G, Killeen GF, Knols BGJ, Becker N. The practical importance of permanent and semipermanent habitats for controlling aquatic stages of Anopheles gambiae sensu lato mosquitoes: operationa observations from a rural town in western Kenya. Trop Med Int Health. 2004;9:1274-89.

20. Yawson AE, McCall PJ, Wilson MD, Donnelly MJ. Species abundance and insecticide resistance of Anopheles gambiae in selected areas of Ghana and Burkina Faso. Med Vet Entomol. 2004;18:372-7.

21. de Souza D, Kelly-Hope L, Lawson B, Wilson M, Boakye D. Environmental factors associated with the distribution of Anopheles gambiae s.s. in Ghana; an important vector of lymphatic filariasis and malaria. PLoS One. 2010;5:e9927.

22. Tene Fossog B, Ayala D, Acevedo P, Kengne P, Abeso Mebuy INA. Habitat segregation and ecological character displacement in cryptic African malaria mosquitoes. Evol Appl. 2015;8:326-45.

23. Simard F, Ayala D, Kamdem G, Pombi M, Etouna J, Ose K, et al. Ecological niche partitioning between Anopheles gambiae molecular forms in Cameroon: the ecological side of speciation. BMC Ecol. 2009;9:17.

24. Costantini C, Ayala D, Guelbeogo W, Pombi M, Some C, Bassole I, et al. Living at the edge: biogeographic patterns of habitat segregation conform to speciation by niche expansion in Anopheles gambiae. BMC Ecol. 2009;9:16.

25. Gimonneau G, Pombi M, Choisy M, Morand S, Dabire RK, Simard F. Larval habitat segregation between the molecular forms of the mosquito Anopheles gambiae in a rice field area of Burkina Faso, West Africa. Med Vet Entomol. 2012;26:9-17.

26. Mireji PO, Keating J, Hassanali A, Mbogo CM, Muturi MN, Githure Jl, et al. Biological cost of tolerance to heavy metals in the mosquito Anopheles gambiae. Med Vet Entomol. 2010;24:101-7.
27. Reisen WK, Meyer RP, Shields J, Arbolante C. Population ecology of preimaginal Culex tarsalis (Diptera: Culicidae) in Kern County, California. J Med Entomol. 1989;26:10-22.

28. Kudom AA, Mensah BA, Froeschl G, Boakye D, Rinder H. Preliminary assessment of the potential role of urbanisation in the distribution of carbamate and organophosphate resistant populations of Culex species in Ghana. Parasit Vectors. 2015;8:8.

29. Yawson AE, Weetman D, Wilson MD, Donnelly MJ. Ecological zones rather than molecular forms predict genetic differentiation in the malaria vector Anopheles gambiae s.s. in Ghana. Genetics. 2007;175:751-61.

30. Opoku AA, Ansa-Asare OD, Amoako J. The occurrences and habitat characteristics of mosquitoes in Accra, Ghana. West Afr J Appl Ecol. 2007;11:81-6

31. Kabula BI, Attah PK, Wilson MD, Boakye D. Characterization of Anopheles gambiae s.l and insecticide resistance profile relative to physicochemical properties of breeding habitats within Accra Metropolis, Ghana. Tanzania J Health Res. 2011;13:3.

32. Kudom AA, Mensah BA, Agyeman TK. Characterization of mosquito larval habitats and assessment of insecticide-resistance status of Anopheles gambiae senso lato in urban areas in south western Ghana. JVector Ecol. 2012;37:77-82.

33. Keating J, Macintyre K, Mbogo C, Githure Jl, Beier J. Characterization of potential larval habitats for Anopheles mosquitoes in relation to urban land-use in Malindi, Kenya. Int J Health Geogr. 2004;3:9.

\section{Submit your next manuscript to BioMed Central and take full advantage of:}

- Convenient online submission

- Thorough peer review

- No space constraints or color figure charges

- Immediate publication on acceptance

- Inclusion in PubMed, CAS, Scopus and Google Scholar

- Research which is freely available for redistribution

Submit your manuscript at

www.biomedcentral.com/submit

C BioMed Central 